\title{
Detection of drought tolerant sugarcane genotypes (Saccharum officinarum) using lipid peroxidation, antioxidant activity, glycine-betaine and proline contents
}

\author{
S. R. Abbas ${ }^{1}$, S.D. Ahmad ${ }^{2}$, S.M. Sabir ${ }^{3 *}$, A.H. Shah ${ }^{4}$
}

${ }^{1}$ Department of Plant Breeding and Molecular Genetics, Faculty of Agriculture, University of Poonch Rawalakot A.K. Pakistan. ${ }^{2}$ University of Azad Jammu and Kashmir, Muzaffarabad A.K. Pakistan. ${ }^{3}$ Department of Chemistry, University of the Poonch Rawalakot Azad Kashmir Pakistan. ${ }^{4}$ Faculty of Business and Administrative Sciences, Kotli, University of Azad Jammu and Kashmir AK Pakistan. "Corresponding author: mubashersabir@yahoo.com

\begin{abstract}
Thirteen genotypes of sugarcane were exposed to different drought stress intensities followed by a period of stress relief. Different biomarkers were used to analyze the stress tolerance in leaves which include DPPH activity, proline, glycine betaine, lipid peroxidation and phenolic contents against different doses of Polyethylene glycol. Relatively the concentrations of all biochemical markers were increased when PEG concentration was increased. On the basis of lipid peroxidation, glycine betaine and proline contents, HSF-242, Lho-83, HSF-240, CP-77-400, CPF-198, NSG-45, NSG-60 and NSG-555 were found to be drought tolerant genotypes. In conclusion the drought stress-induced changes are reversible, at the cellular level in sugarcane.
\end{abstract}

Keywords: Sugarcane, proline, glycine betaine, lipid peroxidation, phenolic contents, antioxidant activity, Polyethylene glycol

\section{Introduction}

Drought stress is an ever-growing crisis that severely limits crop production worldwide and causes important agricultural losses mainly in arid and semiarid areas (Boyer et al., 1982). Drought induced osmotic stress triggers a wide range of perturbations ranging from growth and water status disruption to the alteration of ion transport and uptake systems (Lutts et al., 1996; Bajji et al., 2000). Upon disclosure to water deficit, plants exhibit physiological, biochemical and molecular responses at both the cellular and whole plant levels (Hasegawa et al., 2000). Generally, the plants accumulate some kind of organic and inorganic solutes in the cytosol to raise osmotic pressure and thereby maintain both turgor and the driving gradient for water uptake (Rhodes and Samaras, 1994). Among these solutes, proline is the most widely studied (Delauney and Verma, 1993). It has been suggested that the increase of free proline levels is an indicator 
of injury that results from imbalances in other pathways pathways (Bhaskaran et al., 1985; Perez-Alfocea and Lahrer, 1995). Also, the beneficial roles of proline in conferring osmotolerance have been widely reported (Bajji et al., 2000). Reactive oxygen species (ROS) such as the superoxide radical, hydrogen peroxide and hydroxyl radical can cause lipid peroxidation and consequently membrane injury which leads to leakage of cellular content, protein degrading, enzyme inactivation, pigment bleaching and disruption of DNA strands and thus cell death (Scandalios, 1993). Enhanced production of oxygen free radicals is responsible for peroxidation of membrane lipids and the degree of peroxides damage of cell was controlled by the potency of peroxidase enzyme system (Sairam and Tyagi, 2004). Plants have developed a series of both enzymatic and non-enzymatic detoxification systems to counteract antioxidant system, thereby protecting cells from oxidative damage (Sairam and Tyagi, 2004).

Polyethylene Glycol (PEG) induces water stress in plants (Ruf et al., 1967; Kaufman and Eckard, 1971). PEG is a non-penetrating inert osmoticum that lowers the osmotic potential of nutrient solutions, but it is not taken and is not phytotoxic (Lawlor, 1970). PEG stimulates water stress in cultured plant cells in the same way it does in the cells of intact plants (Azhar et al., 2012).

Sugarcane accounts for approximately $65 \%$ of world sugar production (Carson and Botha, 2002). Sugarcane, being a salt-sensitive crop, is affected in terms of cane quality when exposed to salt stress (Wahid et al., 1997). Hence, there is a constant need to develop new techniques, including plant tissue culture, for improving the tolerance of this crop. So, the objective of the present work was to scrutinize (i) the potential sugarcane cultivars for better performance under drought stress induced by PEG (ii). the pattern of accumulation and growth of glycine betaine, proline, MDA (malondialdehyde) and total phenolics in the leaves of thirteen cultivars of sugarcane under drought stress. This is the first report on the drought stress of cultivars of sugarcane from Pakistan.

\section{Material and Methods}

\subsection{Plant material}

The plant material (varieties and lines) was chosen on the basis of their repeated cultivation in the growing area. Sugarcane (Saccharum officinarum L.) was collected from different research stations of sugarcane growing areas of Pakistan. The experiments were conducted on thirteen genotypes which are HSF240, SPF-213, CP-77-400, CP-43-33, HSF-242, NSG-60, NSG-45, CPF-198, Lho 83-153, NSG-555, CSSG-668, S-2003-US-718 and S-2002-US-133. All genotypes were cultivated in RCBD (Randomized Complete Block Design) in the glasshouse of Faculty of Agriculture Rawalakot Pakistan.

\subsection{Polyethylene glycol treatment}

Plants were grown in pods in RCBD design with three replications. Five treatment of PEG were applied to the plants. T1: control, T2: 5\%, T3: 7.5\%, T4:10\% and $\mathrm{T} 5: 12.5 \%$. Equal amount of farm yard manure were applied to the plants. Newly growing leaves were collected for the experiments.

\subsection{Antioxidant activity by DPPH radical scavenging}

The antioxidant behavior of the sugarcane extracts were measured using the stable DPPH radical according to the method of Hatano et al. (2002). Briefly $0.25 \mathrm{mM}$ solution of DPPH radical $(0.5 \mathrm{ml})$ was added to the sample solution in ethanol $(1 \mathrm{ml})$ at a concentration $(300 \mu \mathrm{g} / \mathrm{ml})$. The mixture was shaken vigorously and left to stand for 30 minutes in the dark, and the absorbance was measured at 517 $\mathrm{nm}$. The scavenging capacity of the DPPH radical was calculated using the following equation: $(\%)=$ $[(\mathrm{Ao}-\mathrm{A} 1) / \mathrm{Ao})] \times 100$, Where, Ao is the absorbance of the control reaction and $\mathrm{A} 1$ is the absorbance of the sample itself. All experiments were carried out in triplicate. 


\subsection{Estimation of lipid peroxidation}

Lipid peroxidation was measured as malondialdehyde (MDA) in the leaves by the method of Cakmak and Horst (1991). This method is based on the reaction with thiobarbituric acid. Fresh leaves $(1.0 \mathrm{~g})$ were ground appropriately in $20 \mathrm{ml}$ of $0.1 \%$ trichloroacetic acid (TCA) solution and centrifuged for $10 \mathrm{~min}$ at $12000 \mathrm{~g}$. One $\mathrm{ml}$ of the supernatant was treated with $4 \mathrm{ml}$ of $20 \%$ TCA solution comprising $0.6 \%$ thiobarbituric acid and thereafter it was heated for 30 minutes at $95 \mathrm{oC}$ in a water bath and then cooled on ice. After centrifugation for 10 minutes at $12000 \mathrm{~g}$, the absorbance of the supernatant was read at 532 and 600 $\mathrm{nm}$. The contents of MDA were worked out using the extinction coefficient of $155 \mathrm{mM}^{-1} \mathrm{~cm}^{-1}$ by using the formula:

MDA level $(\mathrm{nmol})=\Delta($ A $532 \mathrm{~nm}-\mathrm{A} 600 \mathrm{~nm}) / 1.56 \times 10^{5}$

\subsection{Phenolics content}

The total phenolic content was determined by adding $0.5 \mathrm{ml}$ of the aqueous extract to $2.5 \mathrm{ml}, 10 \%$ FolinCiocalteau's reagent $(\mathrm{v} / \mathrm{v})$ and $2.0 \mathrm{ml}$ of $7.5 \%$ sodium carbonate. The reaction mixture was incubated at 45 ${ }^{\circ} \mathrm{C}$ for $40 \mathrm{~min}$, and the absorbance was measured at $765 \mathrm{~nm}$ in the spectrophotometer. Gallic acid was used as a standard phenol (Singleton et al., 1999). The mean of three readings was used and the total phenol content was expressed as milligram's of gallic acid equivalents/g extract.

\subsection{Determination of proline contents}

The proline contents were estimated by the method of Bates et al. (1973). The plants material was homogenized in $3 \%$ aqueous sulfosalicylic acid and the homogenate mixture was centrifuged at 10000 rpm. Supernatant was used for estimation of proline contents. The reaction mixture consisted of $2 \mathrm{ml}$ acid ninhydrin and $2 \mathrm{ml}$ of glacial acetic acid, which was boiled at $100^{\circ} \mathrm{C}$ for $1 \mathrm{~h}$ after termination of reaction in ice bath. The reaction mixture was extracted with $4 \mathrm{ml}$ of toluene and absorbance was read at $520 \mathrm{~nm}$.

\subsection{Determination of glycine betaine contents}

The amount of glycine betaine was estimated by using the method designed by Grieve and Grattan (1983). The plants tissues was finely ground, mechanically shaken with $20 \mathrm{ml}$ of deionized water for $24 \mathrm{~h}$ at $25^{\circ} \mathrm{C}$. The samples were then filtered and the filtrates were diluted (1:1) with $2 \mathrm{~N} \mathrm{H}_{2} \mathrm{SO}_{4}$. Aliquots were kept in centrifuge tubes and cooled in ice water for $1 \mathrm{~h}$. Cold KI-I $\mathrm{I}_{2}$ reagents were added and the reactants were gently stirred with a vortex mixture. The tubes were stored at $4{ }^{\circ} \mathrm{C}$ for $16 \mathrm{~h}$ and then centrifuged at $10000 \mathrm{rpm}$ for $15 \mathrm{~min}$, while the supernatant was carefully recovered with a fine glass tube. The periodide crystals were dissolved in $9 \mathrm{ml}$ of 1,2- dichloroethane. After $2 \mathrm{~h}$, the absorbance was measured at $365 \mathrm{~nm}$. Glycine betaine content was estimated by using a standard curve and expressed in $\mu \mathrm{mol} / \mathrm{g}$ of leaves.

\subsection{Statistical analysis}

The results were expressed as mean \pm standard deviation. The data were analyzed statistically by one way ANOVA and different group means were compared by Duncan's multiple range test (DMRT); $p<0.05$ was considered significant in all cases. The software package Statistica (version 4.5) was used for analysis of data.

\section{Results and Discussion}

\subsection{DPPH radical scavenging activity}

Antioxidant constituents of plant origin are very important substances that have the ability to defend the body from injuries caused by free radical induced oxidative stress (Ahmad et al., 2010). Regenerated plants can build up secondary metabolites similar to those found in the parent plant. Antioxidant potential in regenerated leaves solutions of $S$. officinarum was determined by using $\mathrm{DPPH}^{\circ}$-free radical (Figure 1). 


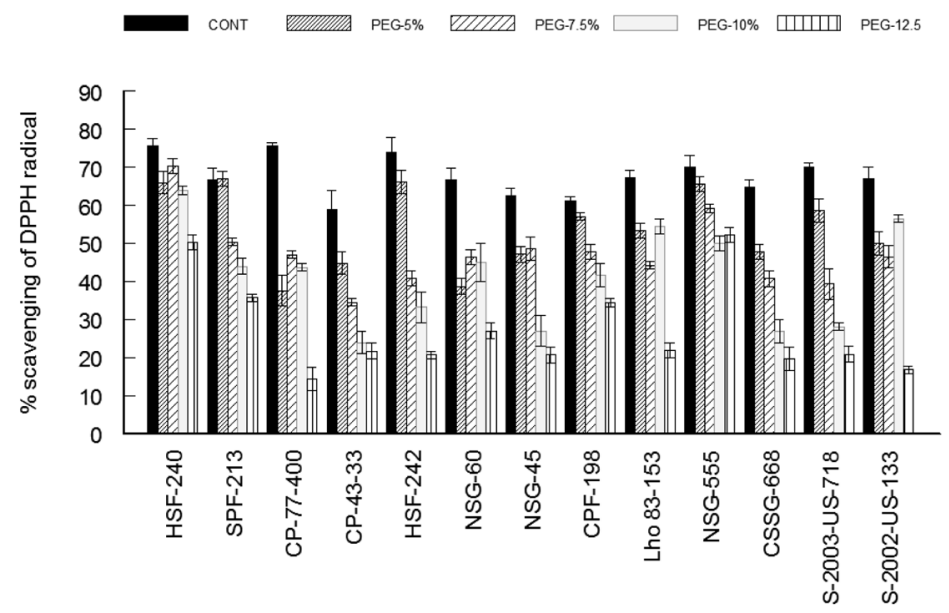

Figure 1. DPPH activity of different cultivars of sugarcane under drought stress induced by different doses of $\mathrm{PEG}$ at $300 \mu \mathrm{g} / \mathrm{ml}$. Values are mean $\pm \mathrm{SD}$.

Figure 1 shows the radical scavenging activity of different genotypes. The genotypes showed very high radical scavenging activity at control level. HSF-242, HSF-240, CP-77-400, S-2003-US-7181 and S-2002US-1331 showed the high antioxidant activity. NSG555-100 and CPF-198-100 are potential candidates of antioxidant activity as their scavenging percentage was found to be higher than $70 \%$. With the application of PEG the antioxidant activity of all genotypes decreased and the maximum decrease was found at the highest dose of PEG (12.5\%). HSF-242 and SPF-213-100 showed the drought tolerance as their scavenging percentage were found to be $50.2 \%$ and $35.6 \%$ at a PEG (12.5\%) dose. NSG-555-100 and CPF-198-100 showed the obvious tolerance as their scavenging percentage was resistant to change with the application of PEG. High level of DPPH activity has been correlated with tolerance to different stress conditions (Kang and Salveit, 2000) but at the same time, they might point towards a source of easy accessible food supplement or its pharmaceutical industry. These results are in line with the other studies (Pei-Ying Yu, 2009; Abbas et al., 2013).

\subsection{Lipid peroxidation}

Lipid peroxidation as MDA content was found to be different among different wheat cultivars (Figure 2). Lipid peroxidation showed increasing trend with increasing doses of PEG. The tolerance of genotypes to salt stress is reflected by lower lipid peroxidation. Among different cultivars (control) MDA level varied from $26.8-45.57 \mathrm{nmol} / \mathrm{g}$ of fresh leaves. The minimum increase in MDA was detected in HSF-242, NSG-45 and Lho- 83 and thus these genotypes can be declared as drought tolerant. Lipid peroxidation requires energy and involves the production of superoxide radical $\left(\mathrm{O}^{2-}\right)$. The other highly reactive chemical species are singlet oxygen $\left({ }^{1} \mathrm{O}_{2}\right)$, hydroxyl free radical $(\mathrm{OH})$ and hydrogen peroxide $\left(\mathrm{H}_{2} \mathrm{O}_{2}\right)$, which stimulates lipid peroxidation (Fridovic, 1986). 


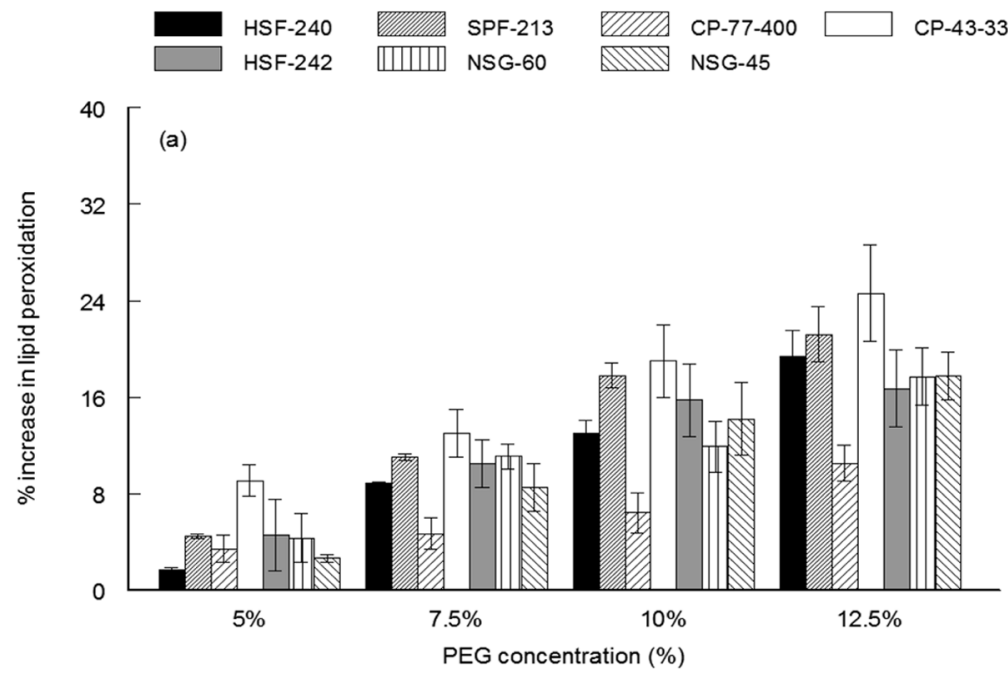

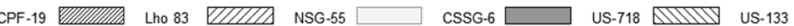

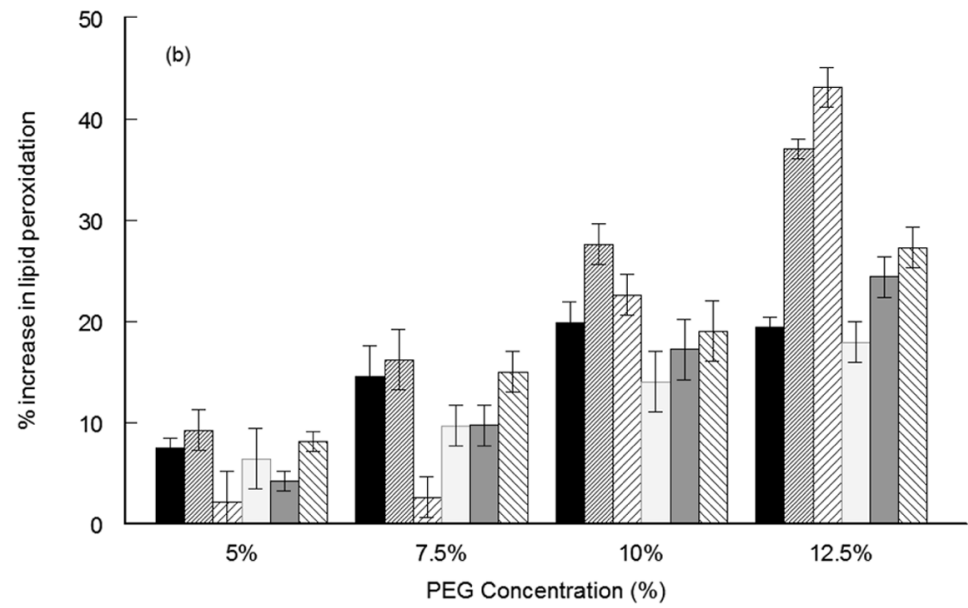

Figure 2. Increase in Lipid peroxidation among different cultivars of sugarcane with different doses of PEG. Values are mean $\pm \operatorname{SD}(n=3)$ 


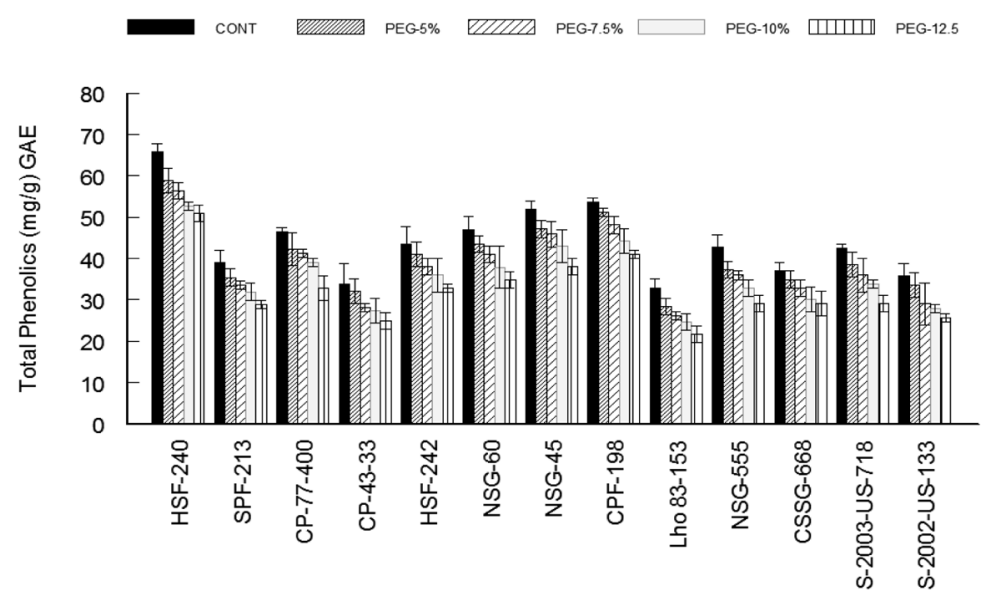

Figure 3. Change in phenolic content among different cultivars of sugarcane with different doses of PEG. Values are mean $\pm \mathrm{SD}(\mathrm{n}=3)$.

The stress induces increase in leaf membrane damage, the release of $\mathrm{CO}_{2}$ into the atmosphere as a result of tiny stomata, decreased hydrolytic enzyme activity and increased lipid peroxidation level (Noctor and Foyer, 1998). Allen (1995) also reported that much of injury to plants caused by various stresses is associated with oxidative damage at cellular level such as cell membrane damage.

\subsection{Total phenolic content of sugarcane}

To assess the sugarcane in relation to their health benefits and in the credentials of potential constituents for the development of functional diet the total antioxidant scavenging capacity, total phenols content (TPC) have extensively been used (Abbas et al., 2014). Total phenolic content ranged from $32.9-65.7 \mathrm{mg} / \mathrm{g}$ of gallic acid equivalent in leaves (Figure 3). Treatment with different PEG doses caused a concentration dependent decrease in phenolic content. However, this decrease was not significant $(p>0.05)$. The cultivars HSF-242, CPF198, NSG-45 relatively contained high quantity of phenolic content compared to other cultivars (Figure 3) which might be responsible for their high antioxidant activity. At control level, the total phenolic content ranged from 32.9-65.7 mg/g which was decreased to $21.75-50.87 \mathrm{mg} / \mathrm{g}$ at the highest dose of PEG. HSF-240 showed maximum results against PEG at a control of $42.4 \mathrm{mg} / \mathrm{g}$ and minimum result are shown by S-2003-US-718 is $27.2 \mathrm{mg} / \mathrm{g}$ (Figure 3) conversely, HSF-240, CP-43-33, HSF242, Lho 83-153 and CSSG-668 showed decline in phenolic contents when PEG concentration is $12.5 \%$. These genotypes don't survive at high concentration of PEG (Figure 3). These results are in agreement to our previous findings on sugarcane cultivars (Abbas et al., 2013).

\subsection{Glycine betaine and proline contents}

Glycine betaine (GB) and proline are the two most important organic osmolytes that accumulate in a variety of plant species in retort to environmental stresses such as extreme temperatures, drought, salinity, UV radiation and heavy metals. Lot of research and articles proved a positive connection between accretion of glycine betaine and proline and plant stress tolerance (Hamdia and Shaddad, 2010; Ashraf and Fooland, 2005). 

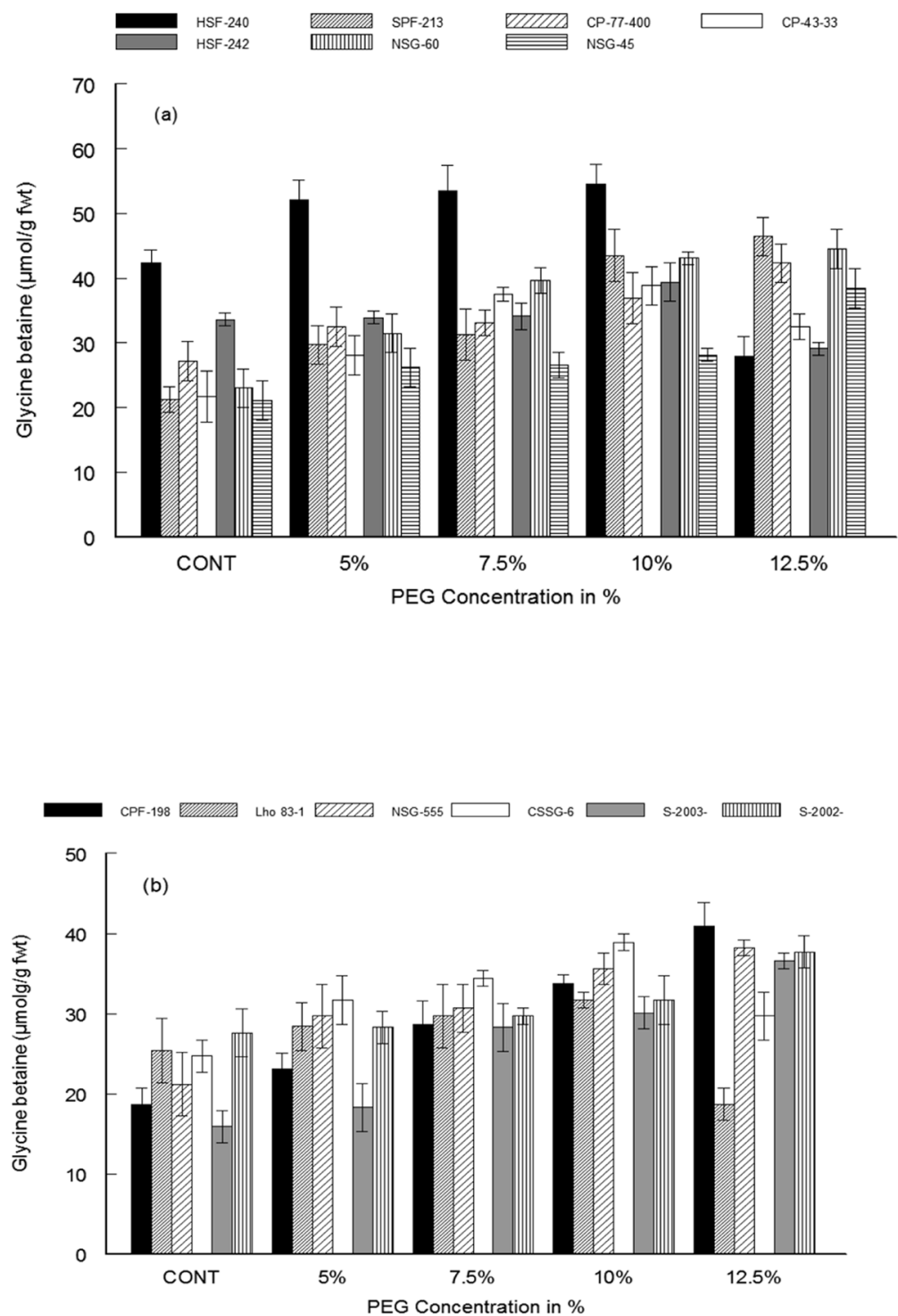

Figure 4. Increase in glycine betaine content among different cultivars of sugarcane with different doses of PEG. Values are mean \pm SD $(n=3)$. 

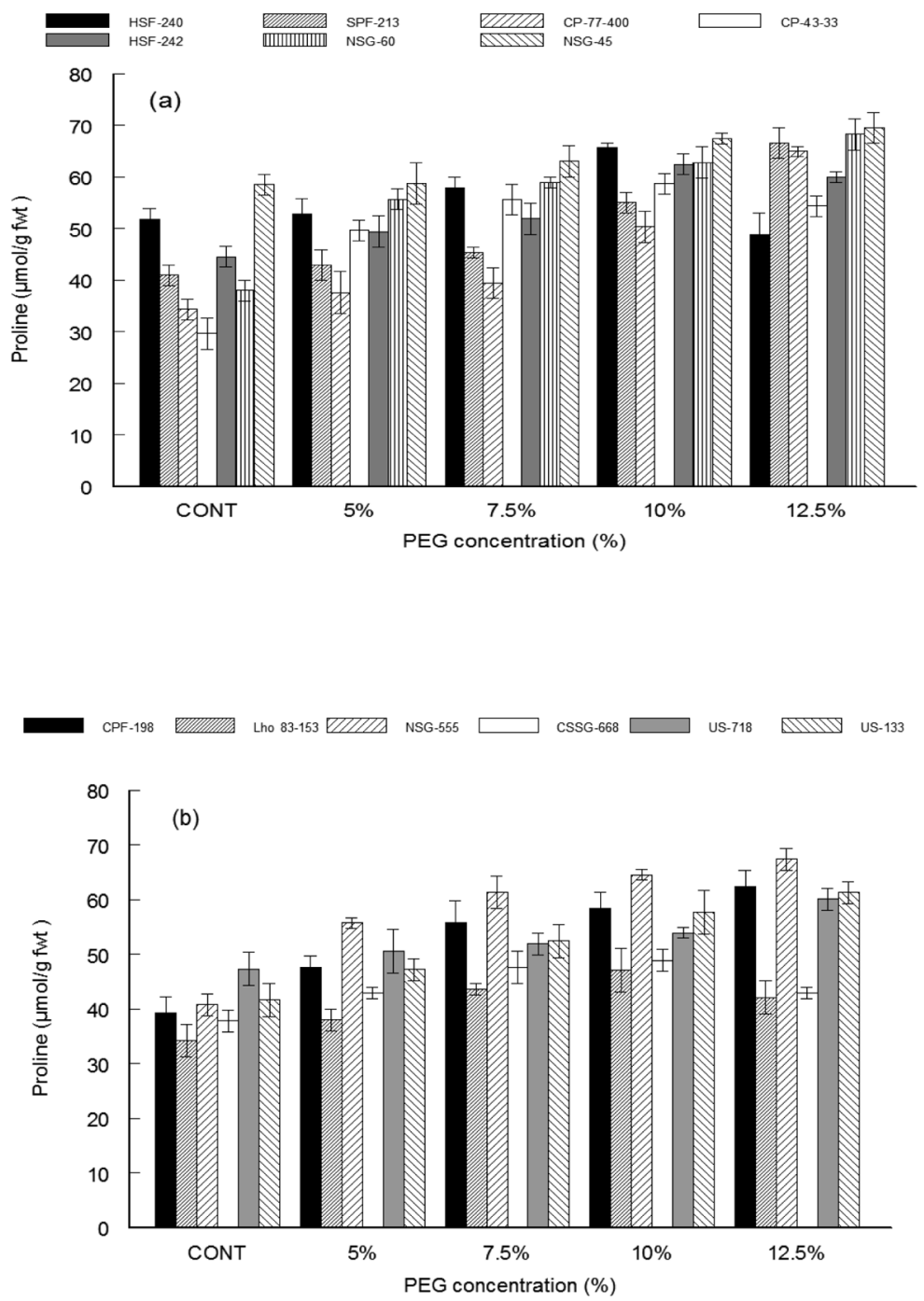

Figure 5. Increase in proline content among different cultivars of sugarcane with different doses of PEG. Values are mean $\pm \operatorname{SD}(\mathrm{n}=3)$. 
Glycine betaine contents mostly increased when PEG concentration increased. Drought stress has profound effect on the glycine betaine accumulation in sugarcane genotypes. The gylcine betaine contents increased under abiotic stresses (Abdul et al., 2007). The estimation glycine betaine serves as physiological marker for stress and provides protection from oxidative stress, which would have otherwise cause damage of cell membrane, protein, DNA structure and inhibition of the photosynthesis will occur under water stress condition (Sairam and Saxena, 2000). At control conditions the production of glycine betaine ranges from 15.9-42.2 $\mu \mathrm{mol} / \mathrm{g}$ and at the maximum level of salt application it ranges from 36.6-46.6 $\mu \mathrm{mol} / \mathrm{g}$ (Figure 4). It is interesting to note that HSF-240 and HSF-242 showed increase in glycine betaine upto $10 \%$ dose of PEG and the maxium dose causes decrease in glycine betaine content. This might be due to the death of leaves at very high dose of PEG. Maximum increased production of glycine betaine was observed in HSF$240(54.6 \mu \mathrm{mol} / \mathrm{g}), \mathrm{CP}-77-400(42.3 \mu \mathrm{mol} / \mathrm{g})$, CPF-198 $(40.9 \mu \mathrm{mol} / \mathrm{g})$ and NSG-555 $(38.2 \mu \mathrm{mol} / \mathrm{g})$ showing the obvious tolerance under salt stress (Figure 4). Proline contents of sugarcane genotypes mostly increased but those genotypes which show decline in glycine betaine also displayed same results in proline concentration. Increased proline accumulation was reported in water stressed sorghum (Abdul et al., 2008). Increased proline in the stressed plants may be an adaptation to overcome the stress condition which constantly supplies energy for growth and survival and thereby helping the plants to tolerate stress (Abdul et. al., 2008). Drought occurs in two ways, which are due to increase of proline, which includes increasing synthesis of proline enzymes levels and decreasing of destructive proline enzyme actions (Rontein et al., 2002). This is because as PEG concentration increased the concentration of proline increased most of the time (Figure 5). The proline contents varied between 29.6-69.9 $\mu \mathrm{mol} / \mathrm{g}$. Maximum proline contents were released in NSG-45 $(69.9 \mu \mathrm{mol} / \mathrm{g})$, NSG$60(68.8 \mu \mathrm{mol} / \mathrm{g}), \mathrm{HSF}-240(65.6 \mu \mathrm{mol} / \mathrm{g})$ and NSG-555 $(67.4 \mu \mathrm{mol} / \mathrm{g})$ while, minimum proline contents was released by CP-43-33 $(29.6 \mu \mathrm{mol} / \mathrm{g})$ in (Figure 5).

\section{Conclusion}

In conclusion, the examined sugarcane varieties exhibited significant difference in their contents of total phenolics as well as their scavenging capacities against free radicals, proline, glycine betaine and MDA production. Certain sugarcane varieties, such as HSF-240, CP-77-400, S-2003-US-7181 and S-2002US-1331 demonstrated the higher antioxidant activities due to their high phenolic contents. On the basis of lipid peroxidation, glycine betaine and proline contents, HSF242, Lho-83, HSF-240, CP-77-400, CPF-198, NSG45 , NSG-60 and NSG-555 were found to be drought tolerant genotypes. However, further biochemical and molecular studies are in progress to indicate the drought resistant genotypes among these cultivars of sugarcane.

\section{References}

Ahmad, N., Fazal, H., Abbasi, B.H., Rashid, M., Mahmood, T., Fatima, N. 2010. Efficient regeneration and antioxidant potential in regenerated-tissues of Piper nigrum L. Plant Cell Tissue Organ Culture. 102, 129-134.

Allen, R.D. 1995. Dissection of oxidative stress tolerance usingtransgenic plants. Plant Physiology. 107, 1049-1054.

Abdul Jaleel, C., Sankar, B., Manivannan P., Kishorekumar, A., Sridharan, R., Panneersevam, R. 2007. Calcium chloride effect on salinity induced oxidative stress, proline metabolism and indole alkaloid accumulation in Catharanthus roseus. Comptes Rendes Biologies. 330, 674-683.

Abbas S.R., Ahmad, S.D. Sabir, S.M. Shah, A.H., Shahid, A., Gohar, M. Arif, S. Rao, A.Z. 2013. Antioxidant activity, repair and tolerance of oxidative DNA damage in different cultivars of Sugarcane (Saccharum officinarum) leaves. Australian Journal of Crop Science. 7, 40-45. 
Abbas, S.R., Sabir, S.M., Ahmad, S.D., Boligon, A.A., Athayde, M.L. 2014. Phenolic profile, antioxidant potential and DNA damage protecting activity of sugarcane (Saccharum officinarum). Food Chemistry. 147, 10-16.

Abbas, S.R., Ahmad, S.D., Sabir, S.M., Wajid, A., Aiya, B., Abbas, M.R., Sabir, H.S. 2013. Screening of drough tolerant genotypes of sugarcane through biochemical markers against polyethylene glycol. International Journal of Scientific and Engineering Research. 4, 980-988.

Abdul Jaleel, C., Manivannan P., Kishorekumar, A., Sridharan, R., anneersevam, R.P. 2008. Salt stress mitigation by calcium chloride in Phyllanthus amarus. Acta Botanica Croatica. 67, 53-62.

Ashraf M., Leary, J.W.O. 1996. "Effect of Drought Stress on Growth, Water Relations and Gas Exchange of Two Lines of Sunflower Differing in Degree of Salt Tolerance." International Journal of Plant Sciences. 157, 729-732.

Ashraf, M., Foolad, M.R. 2005. Pre sowing seed treatment: A shotgun approach to improve germination, plant growth and crop yield under saline and non saline conditions. Advances in Agronomy. 88, 825-831.

Azhar, H.S., Safdar, H.S., Habib, A., Zahoor, A.S., Fida, M.A., Farhatullah, A., Abrar, H.S. 2012. Adaptation to polyethylene stress mentains totipotency of cell lines of Oryza sativa L. Swaft-1 for a longer period. Pakistan Journal of Botany. 44, 313-316.

Boyer, J.S. 1982. Plant productivity and environment. Science. 218, 443-448.

Bhaskaran, S., Smith, R.H., Newton, R.J. 1985. Physiological changes in cultured sorghum cells in response to induced water stress. Plant Physiology. 79, 266-269.
Bates, L.S., Waldern, R.P., Teare, I.D. 1973. Rapid assay for determination of free proline for water stress studies. Plant and Soil. 39, 205-207.

Bajji, M., Lutts, S., Kinet, J.M. 2000. Physiological changes after exposure to and recovery from polyethylene glycol-induced water deficit in callus cultures issued from durum wheat (Triticum durum Desf.) cultivars differing in drought resistance. Journal of Plant Physiology. 156, 75-83.

Carson, D.L., Botha, F.C. 2002. Genes expressed in sugarcane maturing internodal tissue. Plant Cell Reporter. 20, 1075-1081.

Cakmak, I., Horst, J. H. 1991. Effects of aluminum on lipid peroxidation, superoxide dismutase, catalase, and peroxidase activities in root tips of soybean (Glycine max). Physiologia Plantarum. 83, 463468.

Delauney, A.J., Verma, D.P.S. 1993. Proline biosynthesis and osmoregulation in plants. Plant Journal. 4, 215-223.

Fridovich, I. 1986. Biological effects of superoxide radical. Archives of Biochemistry and Biophysics. 247, 1-11.

Grieve, C.M., Grattan, S. R. 1983. Rapid assay for determination of water soluble quanternary ammonium compounds. Plant and Soil. 70, 303307.

Hasegawa, P., Bressan, R.A., Zhu, J.K., Bohnert, H.J. 2000. Plant cellularand molecular responses to high salinity. Annual Reviews of Plant Physiology and Molecular Biology. 51, 463-499.

Hatano, T., Kagawa, H., Yasuhara, T., Okuda, T. 1988. Two new flavonoids andother constituents in licorice root; their relative astringency and radicalscavenging effects. Chemical and Pharmaceutical Bulletin. 36, 2090-2097. 
Kang, H.M., Salveit, M .E. 2002. Reduced chilling tolerance in elongating cucumber seedling. Radicals is related to their reduced antioxidant enzyme and DPPH radical scavenging activity. Physiologia Plantarum. 115, 244-250.

Kaufman, M.R., Eckard, A.N. 1971. Evaluation of water stress control with PEG by analysis of guttation. Plant Physiology. 47, 453-458.

Lutts, S., Kinet, J. M., Bouharmont, J. 1996. Effects of various salts and ofmannitolon ion and proline accumulation in relation to osmotic adjustment in rice (Oryza sativa L.) callus cultures. Journal of Plant Physiology. 149, 186-195.

Lawlor, D.W. 1970. Absorption of PEG by plants and their effects on plant growth. New Phytologist. 69, 501-513.

Noctor, G., Foyer, C.H. 1998. Ascorbate and glutathione: keeping activeoxygen under control. Annual Review of Plant Physiology and Plant Molecular Biology. 49, 249-279.

Pei-ying, Yu. 2009. Antioxidant and anticancer activities of Sugarcane (Saccharum officinarum L.) leaf of different varieties. M.Sc (thesis). Graduate institute of Biotechnology, China.

Perez-Alfocea, F., Larher, F. 1995. Sucrose and proline accumulation and sugar efflux in tomato leaf discs affected by $\mathrm{NaCl}$ and polyethylene glycol 6000 iso-osmotic stresses. Plant Science. 107, 9-15.
Rhodes, D., Samaras, Y. 1994. Genetic control of osmoregulation in plants.In cellular and molecular physiology of cell volume regulation. Strange K. Boca Raton: CRC Press. pp: 347-361.

Rontein, D., Basset, G., Hason, A.D. 2002. Metabolic engineering of osmo-protectant accumulation in plants. Metabolic Engineering. 4, 49-56.

Ruf, R.H., Eckard, E.R., Gifford, R.O. 1967. Compounds of osmotic adjustment of plants to rapid changes in root medium osmotic pressure. Soil Science. 104, 159-62.

Sairam, R. K., Tyagi, A. 2004. Physiology and molecular biology of salinity stress tolerance in plants. Current Science. 86, 407-421

Sairam, R.K., Saxena, D.C. 2000. Oxidative stress and Antioxidants in wheat genotypes: Possible mechanism of water stress tolerance. Journal of Agronomy and Crop Science. 184, 55-61.

Singleton, V.L., Orthofer, R., Lamuela-Raventos, R.M. 1999. Analysis of total phenols and other oxidation substrates and antioxidants by means of FolinCiocalteu,s reagent. Methods in Enzymology. 299, 152-178.

Scandalios, J.G. 1993. Oxygen stress and superoxide dismutases. Plant Physiology. 101, 7-12.

Wahid, A., Rasul, E., Rao, A.R. 1997. Germination responses of sensitive and tolerant sugarcane lines to sodium chloride. Seed Science and Technology. $25,465-470$. 